\title{
Sustainable Development of Energy under the Perspective of Ecological Civilization
}

\author{
Liying Yin ${ }^{a}$, Enze Liu ${ }^{b}$ \\ Jilin Agricultural University, Changchun 130018, China \\ aylyjlnd@126.com, blgjswxy@126.com
}

Keywords: Ecological civilization; Energy security; Sustainable development.

\begin{abstract}
Ecological civilization is human society and the natural environment of equality, common, sustainable development for the purpose of civilization development. Energy is the material basis of the premise of the economic and social development, there is no human civilization and social progress without energy. The party's 18 report made it clear that the construction of ecological civilization into the overall layout of building socialism with Chinese characteristics. But energy security is increasingly becoming the biggest obstacle to the realization of ecological civilization. To guarantee energy security, which is the key to sustainable energy development. And the only way to construction of ecological civilization.
\end{abstract}

\section{Introduction}

The first, Energy: The driving force of the development of human civilization

Energy also known energy resources, which means can produce a variety of energy (such as heat energy, electric energy, light energy and mechanical energy, etc.) or collectively material can be used for power refers directly to obtain or through processing, conversion and obtain useful capable of a variety of natural resources. Uneven distribution of energy on Earth, energy reserves and the quality is also very different, and most limited energy reserves, with the development and use of energy gradually reduced until exhausted.

Energy species rich and varied. Press for ways energy can be divided into two categories: primary energy, such as coal, oil, natural gas, wind, hydro, etc.; Second, secondary energy, such as electric, steam, coke, coal gas, hydrogen. According to whether renewable energy can be divided into two categories: First, renewable energy, water energy, wind energy, tidal energy, solar energy, etc.; second are non-renewable energy sources, such as oil, coal, nuclear fuel, natural gas. According to the degree of utilization of energy can be divided into two categories: First, conventional energy sources such as coal, oil, natural gas, fuel wood fuel, hydro energy, wind energy, etc.; Second, new energy sources, such as geothermal energy, solar energy, biomass energy, tidal energy. The degree of pollution of the environment by energy can be divided into two categories: First, clean energy, such as solar energy, hydro energy, wind energy, ocean energy, natural gas, etc.; two non-clean energy, such as coal, oil, firewood fuel.[1]

Throughout the history of human society, every major advancement of human civilization is energy development and utilization of results. The history of human civilization is a history of energy development. In both primitive societies, Agriculture and animal husbandry economic times, humans put firewood and other biomass as a primary energy for cooking, heating, lighting, also used for firing tools. Occasionally use a little water, soil, light, heat and other energy to agricultural production, distribution and abundances of these energy resources also restrict the level of agricultural production, relative to the level of agricultural development in the rich desert soil and water resources along the river basin would be higher. Visible, energy midwiferies agricultural civilization; With the invention of the steam engine and use into the industrial stage of development, coal this "black gold" is mined minerals fuel energy use, causing social productivity, technology, production of a series of changes in the production structure makes big productivity into the machine age. The rapid development of large-scale machine production is huge energy consumption as a precondition protection. To the 19th 
century, the world entered the "coal age." Coal industry completely changed the face of the country, and with unprecedented speed driving history. It created a new type of humanity, opening up a view of the world, life, social and interpersonal new angle, the arrival of the era of industrial civilization. From the beginning of the 1870s, with oil and gas extraction, processing and refining, electric motors, IC Engine, Gas Expander invention, the further development of large-scale machine industry, the world's rapid economic growth, known as "industrial blood" oil deservedly become a major energy industry development and people's lives. 1950s, the world's energy started with the oil and gas-dominated era. Industrial civilization which brought people enjoyment, but also caused ecological problems to be solved, gave birth to the arrival of the era of ecological civilization construction. Thus, energy development and utilization of every leap, have caused changes in production technology, which greatly promoted the development of productive forces, energy is the driving force for the development of human civilization.

\section{Experimental Section}

Second, The problem of Energy security: The biggest obstacle to the realization of ecological civilization

The party's 18 report clearly brought the construction of ecological civilization to construction of building socialism with Chinese characteristics of the overall layout, people and land to achieve balanced and sustainable development. This requires energy as a natural resource, both to a steady supply of clean and efficient use and to protect the needs of economic and social development and steady progress, but also can not be on the economic and social development in the development and utilization process, progress and pose a threat to people's lives, that is energy security, which is energy supply security and energy security of the organic unity.

"Our country is a big country with abundant resources" can be described as rich a true portrayal of China's energy resources. However, large population, the per capita energy is relatively small, and, for a long time, China's economic growth relies mainly on high energy consumption, causing environmental pollution, ecological damage, energy shortages and other issues. The role of energy in economic development of the engine gradually becomes a constraint to economic development, energy security issues affecting sustainable human development is increasingly becoming a deadly killer, which has become the biggest obstacle to construction of ecological civilization.

First, Sustainable Growth of energy demand, increasing pressure on energy supply

For a long time, open type of energy consumption of the formation of the extensive economic growth mode, resulting in the rapid growth of China's energy needs. Especially since the 1990s, more obvious resource constraints, lack of energy supply as a constraint to economic and social development bottleneck. The past 30 years, total energy consumption from 1980's 600 million tons of standard coal sharp increase to 36 million tons of coal in 2012, the total energy consumption [2] in 2013 accounted for the proportion of the world is close to $22.8 \%$, becoming a veritable world energy consumer. [3] Moreover, with the rapid economic growth and the increasing expansion of the total economy of scale, the energy demand will continue to increase rapidly, the pressure of energy supply will increase, the contradiction between the demand and the supply of energy in China became more conspicuous further. In addition, China's automobile production in 2011 amounted to 18.27 million, average annual growth of 2 million, in 2011 amounted to 93.56 million civilian car ownership, average annual growth of 10.32 million. [4] This is a huge demand for energy. Chinese Academy of Sciences research report predicts that in 2020, China's energy demand will reach 2.88 billion -3.88 billion tons of coal, then coal shortfall of about 321 million -1.174 billion tons, a huge oil and gas gap [5].

Second, Rising energy dependence on foreign country, oil security pressure increases

China's energy shortage is not a total shortage, but rather a structural shortage. Fossil Energy who provided the impetus for progress in the world, but the limited fossil energy reserves. Mined based on a comparison with proven reserves, according to the exploitation of 1950, China's coal to be mined in 3816; mined by the year 2000, for the exploitation of 88 years; press mined in 2011, our 33 years after 
no coal to be tapped. From 2009, China became a net importer of coal, imported 270 million tons in 2012, and imported 330 million tons in 2013. From 1993, China became a net oil importer in 2006 became a net importer of natural gas. 2011 British Petroleum (BP) released "World Energy Statistics Yearbook" which said that in 2010 China became the world's largest energy consuming country, where the most serious oil shortage. In 2010, China imported 239 million tons of crude oil, exported 3.03 million tons, domestic production of 203 million tons, external dependence is $53.8 \%$. The degree of external dependence on oil consumption has reached $50 \%$ of the cordon, which illustrates that China is a big country with oil, but also a country which lacked of oil. Because oil is a strategic resource of the world, in a sense, the energy issue is the oil issue, energy security is oil security. [6] Moreover, the state of China's crude oil imports more than $60 \%$ from the Middle East and North Africa region volatile political situation, so that the supply of oil resources insecurity increases.

Third, Coal-dominated energy structure leads to energy inefficient and polluting

China is the only coal-based energy consuming country in the word, also with the highest proportion of coal use in the world. This is inextricably linked with China's "rich in coal, less oil and less gas.", which is the energy characteristics. For a long time, coal accounts for $70 \%$ of primary energy, coal-based energy structure can not be changed in a short time. And our energy technology is relatively backward, comprehensive energy efficiency of approximately 33\%, 10 percentage lower than developed countries, [7] the coal-dominated energy consumption structure causing serious environmental pollution, water shortages exacerbated and ecological barrier destruction. Research shows that every year due to acid rain caused direct economic losses of about $1 \%$ a year $2 \%$ of GNP, the potential loss there may be more than $4 \%$. According to statistics, the total amount of carbon dioxide emissions starting in 2007, ranking first in the world. 2011, China's total carbon dioxide emissions of 8.5 billion tons, accounting for $26.9 \%$ of the global total, per capita emissions of 6.5 tons, exceeding the world average, accounted for 70 percent of carbon dioxide emissions incremental world. In early 2013, fog and haze ravaged the eastern region of our country, its wide range of heavy long time, the pollution called the most historic and world. PM2. 5 "storm table" cause for concern, so that people living environmental conditions limit of tolerance is reached. Environmental issues on the surface of fog and haze, but it reflects the intrinsic energy security issues.

\section{Results and Discussion}

Third, Sustainable energy development: construction of ecological civilization and the only way Energy for sustainable development is an effective way to solve the problem of energy security. Explore a low-input, low consumption, low emission, high-yield, sustainable energy development and utilization of the road, to achieve coordinated development of economy and energy, the environment, and promote the construction of ecological civilization.

(First) Changes in energy consumption patterns in order to achieve energy savings

Energy saving is an attitude, but also a civilization. To advocate healthy and civilized carbon consumption, save energy and protect the environment good society. Government to lead: to cultivate people's awareness of low-carbon with low-carbon consumer culture; improve the government's regulatory policies encourage low-carbon consumption; take the lead in energy conservation, set an example for other sectors. Leading enterprises: enterprise as large energy consumption and carbon emissions, should the value of low-carbon consumption patterns as their assessment criteria; while providing a low-carbon consumer products business as the main body of citizens in shopping malls, supermarkets or markets have a choice to buy low carbon, carbon consumption for all the people laid the material foundation. Social organization promoting: social organization receptive carbon consumption concept, layout advantage of the characteristics of its own, active, broad, deep carry out energy conservation, low-carbon economy, education campaigns, and to practice and promotion. Broad participation of citizens: abandon pomp than lavish, extravagant lifestyle, try to choose a life saving products, add up the drip place, a new era of social values "leader".

(Second)Innovative energy technology to reduce environmental pollution 
Energy production and lag in technology is an important factor for environmental pollution. Sustainable closely related to the rational and efficient use of energy resources and energy. Innovative energy technology, first developed for energy technology innovation, efficient use and reduce pollution. Such as coal, mainly for power generation, and chemical, industrial boilers used in three areas of coal in power generation, we must promote efficient coal technologies, such as ultra (ultra) supercritical power generation technology and integrated gasification combined cycle (IGCC) power generation technologies; in industrial boilers, to promote the construction of highly efficient coal-fired boilers, industrial boilers, such as pulverized coal boiler; coal chemical industry, including coal gasification, coal liquefaction technology, coal-based generation technology; there biomass technologies, including biogas power generation technology, biomass pyrolysis gasification technology, can enhance the value and efficiency in the use of traditional energy industry, but also to reduce carbon emissions, the effective protection of the ecological environment. Second, technological innovation and development of new energy sources, relying on large enterprises, research institutes, promote technological innovation and application of large-scale nuclear power, wind power, solar power, so that humanity gradually out of dependence on traditional energy sources, improve the ecological environment.

(Third)Optimizing energy structure to broaden the energy channels

Optimize the energy structure is an important trend in energy for sustainable development. Reduce the proportion of coal in energy consumption; the development of hydropower, nuclear power as an important measure to promote low-carbon energy mix to clean the direction of development, based on energy technology innovation, accelerate hydropower, nuclear power development pace, constantly developing new and renewable energy energy, actively support biomass energy, wind energy, solar energy, geothermal energy, ocean energy development and utilization, etc., to improve the new energy, energy technology development and utilization of renewable independent innovation capability. Gradually change the existing energy structure, promote the coordinated and sustainable development of China's economy, society and environment.

(Forth)Expand international cooperation in energy, in order to achieve energy security

In today's economic globalization, the world has naturally involved in the world energy market, and the overall situation of the world market with a common fate. Especially high dependence on foreign energy sources in our country, to take full advantage of the domestic market and economic advantages, and actively participate in international energy bilateral and multilateral cooperation in order to ensure the maintenance of a sufficient energy imports ability to pay and acceptable price levels, and participate in and influence the development of energy prices; to safeguard energy (mainly oil) and stable sources of supply, to prevent supply disruptions; energy imports in order to ensure the safety of the transport channel flow.

In short, take the road of sustainable energy has become a major trend. Thus, the transformation of economic growth mode, taking a new road to industrialization, select the resource-saving way of quality and efficiency of development, science and technology leader, and to continue to promote China's ecological civilization construction and environmental protection.

\section{References}

[1]Kai Wu:Huaibei Professional and Technical College Journal, (2012) No.5, p.114.

[2]Information on http:/ /www.stats.gov.cn/tjsj/ndsj.

[3]Wenke Han:Administrative reform,(2014)No.6,p.24.

[4]Yuanchun Shi.Discard Poison Wine and Drink Nectar-Talking about China haze and respond.Science and Technology Daily,2013-02-28.

[5][6][7]Liuqin Chen:Strategic aspect Journal,(2011)No.5,p.13-14. 